\title{
Correction to: The road to Atil: Shlomo Sand, post-Zionism, and the dialectic of Khazaria
}

\section{Anthony Marcus ${ }^{1,2}$}

Published online: 9 February 2022

(c) Springer Nature B.V. 2022

\section{Correction to: Dialectical Anthropology https://doi.org/10.1007/s10624-021-09627-4}

In the originally published online version of the article, the author's affiliation was incorrectly listed as: John Jay College of Criminal Justice, City University of New York, New York, NY, USA. The correct statement is: John Jay College of Criminal Justice of the City University of New York, New York, NY, USA \& The Living With Disability Research Centre, La Trobe University, Bundoora, Australia.

The original article has been corrected.

Publisher's note Springer Nature remains neutral with regard to jurisdictional claims in published maps and institutional affiliations.

The online version of the original article can be found at https://doi.org/10.1007/s10624-021-09627-4

Anthony Marcus

amarcus@jjay.cuny.edu

1 John Jay College of Criminal Justice of the City University of New York, New York, NY, USA

2 The Living With Disability Research Centre, La Trobe University, Bundoora, Australia 